\title{
The Influence of Religious Consciousness on Construction Health and Safety Practices and Performance
}

\author{
"Nnedinma Umeokafor' and Abimbola Windapo²
}

\begin{abstract}
Published online: 30 August 2019
To cite this article: Nnedinma Umeokafor and Abimbola Windapo (2019). The influence of religious consciousness on construction health and safety practices and performance. Journal of Construction in Developing Countries, 24(1): 23-47. https://doi.org/10.21315/jcdc2019.24.1.2.
\end{abstract}

To link to this article: https://doi.org/10.21315/jcdc2019.24.1.2

\begin{abstract}
The potential of religiousness to influence health and safety (H\&S) practices and attitudes, which will in turn determine H\&S performance, is an area that remains highly under-examined. Hence, using the Nigerian construction industry as a case study, this study evaluates the impact of religious consciousness on H\&S practices, H\&S attitudes and H\&S performance, and explains how it is practiced to influence H\&S. It also identifies, evaluates and explains the ways in which religion is instrumental in improving H\&S. The study employs a mixed method research approach involving the use of survey questionnaires and interviews in collecting relevant data. The data collected was analysed thematically and using descriptive and inferential statistics including the Kendall's tau-b test. The findings show strong evidence of elements of religion, for example, the belief in the supernatural and religious underpinned activities in construction organisations. It also shows correlations between $\mathrm{H} \& \mathrm{~S}$ lagging indicators, such as rituals, alteration of works and elements of religion, being afraid or respecting the supernatural. There is a correlation between the element of religion, membership of a religious organisation and the leading H\&S indicators such as conducting H\&S audit. Additionally, it emerged that elements of religion, such as observed belief in the supernatural, correlate with the attitudes of the contractors towards H\&S such as ensuring the safety of the public and preserving the environment. Furthermore, a significant number of the respondents perceived that the promotion of $\mathrm{H} \& \mathrm{~S}$ practices through religious underpinned teachings could be an effective way of improving H\&S practices in Nigeria. This study is a first step in exploring the potentials of religiousness in H\&S improvement. It is also beneficial to academics, policymakers and religious teachers, in promoting improved $\mathrm{H} \& \mathrm{~S}$ performance on construction projects.
\end{abstract}

Keywords: Construction, Health and safety, Morality, Practices, Religious consciousness

\section{INTRODUCTION}

Legal and moral obligations to ensure the health and safety (H\&S) of employees and others that may be affected by the workplace dates back as 5,000 years ago (Eckhardt, 2001; Hughes and Ferrett, 2011; cf. Dabup, 2012). Currently, the two concepts (legal and moral obligations) are among the main reasons for engaging in H\&S. Religion on its own remains consistent over the years as a tool for instilling values in people and people are strongly attached to this (Kheni, Gibb and Dainty, 2010; Mookerjee and Beron, 2005). Granted the moral stance of religion, which is demonstrated to suggest ensuring the safety and health of employees and even occupants of construction projects, a case that underpins the aim of this study is

\footnotetext{
'School of Design, Faculty of Liberal Arts and Sciences, University of Greenwich, UNITED KINGDOM 2Department of Construction Economic Management, University of Cape Town, SOUTH AFRICA

"Corresponding author: nnedinmaik@hotmail.com
} 
made by Eckhardt (2001). Umeokafor (2015) posited that religion can be a tool for improving the challenging state of construction H\&S. Conversely, researchers also noted that it is possible that religious beliefs negatively influence H\&S performance and practices (Allegranzi et al., 2009; Umeokafor, 2015). Although previous studies have examined and discussed morality and H\&S (for example: Eckhardt, 2001; Hughes and Ferrett, 2011), there is a paucity of research on the influence of religiousness on H\&S performance or its indicators. Morals are legal, spiritual or religious underpinned, but it is not known whether the religious angle is more impactful. Earlier research has established the link between H\&S and religion. For example, there is evidence of the positive influence of religion on health practice, specifically hand hygiene or hand washing (Allegranzi et al., 2009). Analogously, Eckhardt (2001) demonstrates the religious underpinnings for ensuring safety in the workplace, while from a construction perspective, Smallwood (2002) establishes a link between religiousness and H\&S. It is tempting to classify religion as the same with or under culture, but both are not the same. People can be of the same culture but of different religions and vice versa and be of the same culture but have no religious beliefs. As a result, studies such as Kheni, Gibb and Dainty (2010), Umeokafor (2015) and Umeokafor and Windapo (2016) that examine the influence of contexts of countries, including culture, on H\&S may sparsely fit into the picture of the discourse but with limited implications in explaining the influence of religiousness on $\mathrm{H} \& S$. Nevertheless, these prior studies have neither established the extent of the impact of religion on H\&S practices nor examined the impact of religious consciousness on $\mathrm{H} \& S$ performance or identified or explained the ways in which religion can improve $\mathrm{H} \& \mathrm{~S}$ on construction projects.

Consequently, the first objective of the study is to assess the impact of religious consciousness on $\mathrm{H} \& \mathrm{~S}$ practices and the second is to examine the impact of religious consciousness on the H\&S performance of contractors. The third objective is to assess the attitudes of contractors to $\mathrm{H} \& \mathrm{~S}$ due to religious consciousness and the fourth, to explore how the practice of religion influences safety on site. The last objective is to identify, assess and explain the ways that religion can be instrumental in improving $\mathrm{H} \& S$ performance. To do this, a review of literature on construction H\&S practices and performance and the suitability of religion as a tool for H\&S improvement is undertaken. The conceptual and analytical framework for the study is outlined followed by research methods used in the study, including the demographic description of Nigeria. This is followed by the results and discussion, thereafter the implications of the research and the conclusion and recommendations section.

\section{LITERATURE SURVEY}

\section{Construction H\&S and Practices}

The poor H\&S record of the construction industry in studies such as Health and Safety Executive (HSE) $(2014 ; 2017)$ and Windapo and Jegede $(2013)$ is attributed to poor H\&S practices (Waziri, Hamma-Adama and Kadai, 2015; Windapo and Jegede, 2013). For instance, Waziri, Hamma-Adama and Kadai (2015) found that, on average, only $45 \%$ of proactive H\&S practices to improving the safety and health (i.e. 18 out of the 39) were taken in the 30 construction sites they investigated in Nigeria. Furthermore, Waziri, Hamma-Adama and Kadai (2015) found no evidence of measures to control or reduce exposure to noise and vibration on 
the construction sites investigated. Conversely, although HSE $(2015 ; 2017)$ reports better H\&S practices in the British construction industry, there is evidence in studies such as HSE $(2014 ; 2017)$ that the H\&S record of the industry is still of concern. In $2016 / 2017$, the construction industry in Britain recorded 30 fatal injuries compared to the annual average of 39 fatal injuries for $2012 / 2013-2016 / 2017$. While the fatal injury rate had "fluctuated with 47 fatalities in 2015/2016 compared with 35 in 2014/2015", fatal injuries in the said construction industry is higher than other industries in the 2016/2017 H\&S records (HSE, 2017: 4).

\section{Overview of H\&S Measures of Performance}

There are many measures of H\&S performance, but those relevant to the reported study are discussed. From an objective parameter perspective, incident-based data such as accident rate, injury rates, number of injuries, near miss, which are lagging indicators or negative performance indicators or retrospective indicators are used (American Bureau of Shipping [ABS], 2012; Idoro, 2011; Sgourou et al., 2010). Idoro (2011) views that the indicators mentioned are reliable because the measurement procedure is standardised across all industries and countries, especially in H\&S. However, these lagging methods face criticism because of their inability to reveal the causal relationship in H\&S performance (Marosszeky et al., 2004; Sgourou et al., 2010); they are negative in reporting (Marosszeky et al., 2004). Also, Idoro (2011) argues that these measures of H\&S performance are undermined in developing countries by inadequate regulations, as incident reporting is not mandatory in the construction industry, so there is a lack of accurate H\&S records.

On the other side of H\&S performance measures are positive performance indicators, leading indicators or prospective indicators, where the effectiveness of H\&S training, safety audits and inspection, safety culture and climate are measured (Idoro, 2011; Sgourou et al., 2010). These indicators are either objective or subjective. The objective leading approach involves using data that have been collected by the organisation over a period of time, while the subjective leading approach involves a safety culture survey (ABS, 2012). Leading indicators establish the causal relationship in H\&S performance measurement (Marosszeky et al., 2004; Sgourou et al., 2010) and aim at motivating improved performance and showing how well an organisation is performing (Sgourou et al., 2010). This is by throwing the spotlight on "...organisation and work process and structures that can influence (H\&S) performance" (Idoro, 2011: 156). In other words, in contrast to incident-based measurements, the leading indicators report the changes that may have taken place as per management efforts to prevent the incidents reported by the incidentbased measurement. However, these leading indicators also have limitations such as measurement (Idoro, 2011; Shaw, 1994) and standardisation of parameters (ABS, 2012; Idoro, 2011; Shaw, 1994). Furthermore, Shaw (1994) notes that leading measures such as prescribed auditing system hinders creativity in organisations in terms of benchmarking tailored towards the needs of organisations.

The background established so far explains the combination of indicators by Sgourou et al. (2010) and Idoro (2011) who has used objective and subjective indicators in a complementary way. However, this may not be possible in all cases in some developing countries such as Nigeria due to unreliable H\&S data. As a result, in the reported study, religious conscious oriented morals, values and behaviours are correlated to outcome of lagging indicators and subjective leading indicators. 


\section{Religion in the Construction Industry and the Concept of Religion as a Tool for Improving H\&S}

Based on the studies by Allegranzi et al. (2009) and Eckhardt (2001), religion is conceptualised in this study as the fundamental practices and beliefs of people in Supreme Being(s). Being a sensitive topic, no reference is made herein to any particular religion.

\section{Overview of the elements of religions}

Allen (2012) notes that religions have the following elements: (1) ritual - this includes prayer and communion, (2) the belief in the supernatural, (3) ethics or standards that guide the member of each religion, (4) the sacredness and (5) a public component, for instance, a place of worship and the fellowship of brethren. Although not covered in Allen (2012), each religion subscribes to a central belief. The literature survey presented in this article demonstrates how these elements of religions inform H\&S decision and practices.

\section{Religion in the construction industry}

The presence of religion in construction is sparsely covered in literature. For example, writing about religious teachings and practices, a few studies (for example: Kheni, 2008) have found evidence of religious practices (including rituals - prayers) on construction sites. In his study involving small and medium construction enterprises in Ghana, Kheni (2008) also found evidence of religious activities (prayer to be specific) at a public component level. Kheni (2008) also found evidence of belief in supernatural intervention in accidents. From the Nigerian perspective, while investigating the contextual factors that influence construction H\&S practices, Umeokafor (2015) observed the belief in the supernatural, an element of religion, among the participants in protecting the workers. This is further discussed in this article.

\section{Demonstrating how the elements of religions improve H\&S}

Moral arguments for H\&S are on spiritual, humanitarian and religious grounds but, in some cases, they are interrelated, especially at the humanitarian and religious levels. While the legal and financial reasons for H\&S continue to thrive, the moral arguments tend to be mostly underpinned by humanitarian reasons.

Religious traditions are based on supernatural punishment (Shariff and Rhemtulla, 2012) of which some are alleged to be on earth and some in the afterlife. These religious beliefs as stated in the introductory sections are perceived to instill values in people (Mookerjee and Beron, 2005) and contribute to ethics in heath practices (Allegranzi et al., 2009). According to Shariff and Rhemtulla (2012), once the belief in heaven and hell holds, the ability of religion to instill values is pronounced. Shariff and Rhemtulla (2012) also note the ability of religious belief to positively impact on crime rate. Specifically, Shariff and Rhemtulla (2012) found higher crime rates in societies that believe more in heaven than those that belief more in hell. The argument here is not that engaging in ethical H\&S practices will definitely lead to eternal life, rather that when people view not engaging in ethical 
H\&S practice as a sin and that they are accountable to a supernatural being for their actions, they may have a rethink on their attitude towards H\&S. This is of course based on the assumption that H\&S is a rational behaviour.

Eckhardt (2001) discusses the moral reasons for ensuring a safe workplace, demonstrating the religious underpinnings for a safe workplace. Among his points relating to the discourse is a Bible verse that he demonstrates supports ensuring safety in construction. Typically, quoting Deuteronomy 22: 8, Eckhardt advocates for biblical support to ensure the safety of guests which can more or less be argued to suggest providing a safe building considering all the possible occupants (Eckhardt, 2001). Deuteronomy 22: 8 states that "when you build a new house, make a parapet around your roof so that you may not bring the guilt of bloodshed on your house if someone falls from the roof" (New International Version of the Bible, 2011 ). Rooftops at the time were sit-out for visitors (Eckhardt, 2001) and perhaps the occupants of the house. Eckhardt (2001) goes on to further underpin his argument with the "Golden Rules". Citing Theosophy Library Online, Eckhardt (2001: 37) demonstrates a moral consensus among many religions in terms of causing harm in that they all agree to the golden rule: do unto others as you would have them do unto you.

From the health dimension, personal hygiene such as hand washing is found to have the support of various religions with some having precise instructions of how and when the hand washing exercises will be conducted (Allegranzi et al., 2009). While some may be for symbolic, ritual reasons, some are for cleansing and hygienic reasons (Allegranzi et al., 2009). This further underscores the link between controlling infections, contamination with substances hazardous to health and religion, and the argument of religion as a tool for improving H\&S.

Smallwood (2002) demonstrates a link between H\&S and religion, covering areas such as economic issues, waste, values, the "Golden Rules", sustainability, accountability, work being a spiritual value. Among Smallwood's arguments is that moral standards strongly stem from religious traditions and that the moral standards will then determine behaviour (Smallwood, 2002). Smallwood's position arguably shapes the ethics and standards of religious people. He goes on to support the religious argument against waste where damage of material, plant and equipment, including injuries and fatalities on site does not only show the link between religion and H\&S (Smallwood, 2002) but also suggests a way of improving H\&S through religious teachings and activities.

All religions have ethics, standards and public components (Allen, 2012) with possible supernatural punishments and earthly punishments from fellow members of the religious faiths. Some religious groups may not want to read in the dailies that a member is involved or is responsible for fatalities on a construction site or even occupants of collapsed buildings. Religious principles require that there should be public accountability in that organisations should ensure public safety (Smallwood, 2002). The point here is that the status of members of the construction industry in the various religious gatherings and the fear of punishment such as "back benching" and the possible consequences may make individuals become more involved in $\mathrm{H} \& \mathrm{~S}$. There is this understanding that members of a religious organisation with high status in the congregation should not be involved in activities that will tarnish the image of the religious organisation because they are expected to lead exemplary lives.

The literature discussion in this section in addition to presenting H\&S practices and measure, also highlights the concept of religion as a tool for improving $\mathrm{H} \& S$, 
emphasises ways by which religion is instrumental in improving H\&S and guiding data collection.

\section{ANALYTICAL AND CONCEPTUAL FRAMEWORK}

Figure 1 shows the analytical and conceptual framework for the study. This stems from the works of Allegranzi et al. (2009), Allen (2012), Eckhardt (2001), Mookerjee and Beron (2005), Shariff and Rhemtulla (2012) and Smallwood (2002).

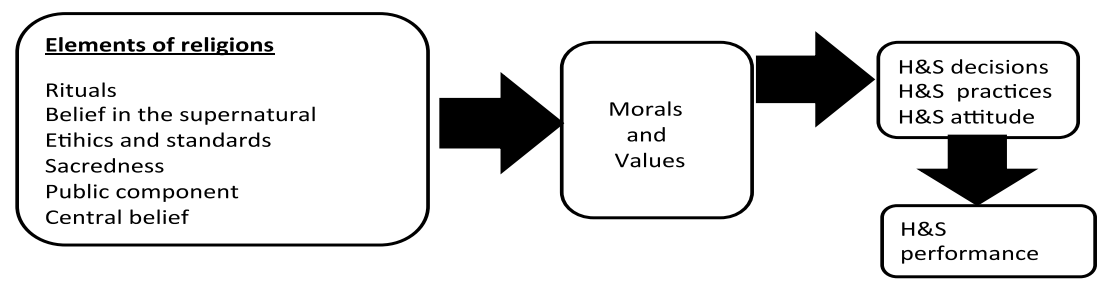

Figure 1. Analytical and Conceptual Framework for the Study

The concept on which the study is based proposes that elements of religion will shape morals and determine the values of people, which will in turn determine their actions in terms of H\&S including H\&S practices (as shown in Figure 1). This is based on the premise that religious traditions directly or indirectly support the goals of H\&S (Eckhardt, 2001; Smallwood, 2002). It can be inferred from the work of Shariff and Rhemtulla (2012) (where the type of religious belief determines the attitude of people towards crime), that religious beliefs may in some cases hinder H\&S practices. This is further emphasised by Umeokafor (2015) who found that $8.1 \%$ of the respondents to an H\&S survey rely on supernatural protection. Although this percentage is insignificant, it however, provides further evidence of the relationship between religious beliefs and H\&S decisions and actions. The outcome of the H\&S practices and decisions will then determine the H\&S performance of the organisation in question. Based on the premise established so far, the study proposes as a guide: the higher the religious consciousness of an organisation, the better their $\mathrm{H} \& \mathrm{~S}$ performance and hypothetically that there is a correlation between religious consciousness and H\&S performance in construction organisations.

\section{METHODS}

\section{Demographics of the Study Area: An Overview}

Nigeria, with a population of about 180 million people is a highly multi-religious nation where according to Pew Forum (2010), in a survey of 2009, 52\% are Muslims, $46 \%$ Christians and the remaining $1 \%$ was other religions or none. While constitutionally, Nigeria may be considered a secular state as noted in Section 10 of the Constitution of the Federal Republic of Nigeria, in practice, it is a multi-religious nation. 
There are six geopolitical zones in Nigeria, North West, North East, North Central, South East, South South, South West and over 250 ethnic groups. The main ethnic groups are Hausa and Fulani (29\%), Yoruba (21\%), Igbo (18\%), ljaw (10\%), Kanuri (4\%), Ibibio (3.5\%) and Tiv (2.5\%) (United States Embassy in Nigeria, 2012). These main tribes in Nigeria tend to reflect the dominant religions in Nigeria. The Hausa tribe in the northern part of Nigeria is mainly Muslims, the Yorubas in the West are divided into Christians and Muslims, while the ljaw tribe in the South and the Igbo tribe in the East are mainly Christians.

According to Ruby and Shah (2017), Nigerians have a high level of religious consciousness. This is because $76 \%$ of the Christians that participated in the study by Ruby and Shah (2017) view "religion as more important to them than their identity as Africans, Nigerians or members of an ethnic group". On the other hand, a higher percentage of Muslims, $91 \%$, view religion as more important to them than their identity as African, Nigeria or members of an ethnic group (ibid). Ruby and Shah (2017) also show the role of the religious affiliation of Nigerians in the political environment of the country.

\section{Data Collection Instrument}

The research adopted a mixed method research approach wherein information was collected by means of a questionnaire and interview instruments. This is because of the ontological position of the research question that requires some constructed information.

For the survey, the data collection instrument was designed based on literature review and discussion with peers and practitioners. Section 1 of the questionnaire identified the demographic profile of the respondents. Section 2 sought to establish the presence of religiousness in construction activities, the lagging indicators such as frequency of hospitalisation rates and illness and leading indicators where $\mathrm{H} \& \mathrm{~S}$ practices were covered e.g. conducting, H\&S audit, H\&S inspections and risk assessment. It is also established the attitude of the organisation towards H\&S because of religious consiousness. Figure 2 shows the variables employed in Section 2 of the questionnaire. The last section then identified and evaluated the ways through which religion improves H\&S performance. The question were in Likert scale ranging from 5 = "Very Frequently" to 1 = "Never" and three "yes", "no" and "unsure" questions for Section 2. Likert scale ranging from 1 = "Strongly Disagree" to 5 = "Strongly Agree" and one "yes", "no" and "unsure" question were for Section 3. The Cronbach's alpha test of reliability showed a value of 0.709 , suggesting an acceptable internally consistent data collection instrument.

For the interviews, the protocol used was designed from the findings of the literature review and survey, opinions and experiences of the authors and consultation with peers. The interview questions were semi-structured and were refined using the four-stage interview protocol refinement framework by CastilloMontoya (2016). The first stage aimed at ensuring that the interview questions were aligned with the research questions/objectives. This entailed checking this against the research questions/objectives to ensure that the right number of interview questions addressed each. The second stage sought to ensure that the questions elicited discussion, were not confrontational, non-judgmental and not offensive. This is vital because of the sensitive nature of the topic. While the third stage sought the feedback on the data instrument, the last stage tested it on construction contractors. 
The first section of the interview protocol sought to identify the profile of participating organisations and respondents; the second section examined how religion is practised to influence H\&S practices. The third section was based on establishing how religion can be used as a medium for improving H\&S. Listed are a few selected indicative interview questions:

1. In your experience, comment on religiousness in relation to H\&S in the Nigerian construction industry.

2. In your experience, describe how rituals, for example prayers, are practised in construction to influence safety on site and/or organisation where you work/ worked.

3. In your experience, describe how belief in the supernatural has influenced or not influenced safety practices/policies on site and/or organisation where you work/worked.

4. Please describe your understanding of the suitability of using religion as a medium for improving H\&S.

5. In your experience, describe how religion can be used as a medium for improving H\&S, if you support this view.

6. In your opinion, describe how religious traditions or teachings can be embedded in H\&S teachings to improve H\&S performance.

7. In your opinion, describe how religiousness can be included in H\&S programmes towards improving H\&S performance.

\section{Sampling and Data Collection}

Through self-administration, the questionnaires were piloted to 30 respondents, which include academics, civil engineers, quantity surveyors and project managers in the Federal Capital Territory (FCT), Anambra, Enugu and Ebonyi states of Nigeria. On receipt of their responses, the questionnaire was revised. The questionnaires were designed based on Figures 1 and 2. The academics were asked to complete the pilot questionnaires based on a recently completed project. It is common practice for academics to have industry roles in addition to academic roles (Umeokafor, 2017).

Authors of various studies have conducted pilot studies, which they used as the population because there is no comprehensive list of contractors, for example Idoro (2012). Consequently, a preliminary survey of contractors was conducted covering the six geopolitical zones of Nigeria, North West, North East, North Central, South East, South South and South West. The preliminary survey showed a total of 400 contractors as the population of the study.

The sample size was calculated with Yamane's formula (Yamane, 1967) (see Equation 1) producing the sample size of 200 which is half of the population.

$$
n=\frac{N}{1+N e^{2}}
$$

where $n$ is the desired sample size to be determined, $N$ is the total population size and $e$ is the level of precision (or accepted error limit). A 95\% confidence level and accepted error limit of 0.05 were adopted for the equation.

Of the questionnaires distributed by hand (with the help of research assistants and colleagues) and electronically, 103 usable ones were returned. This shows a 
$51.5 \%$ response rate. The respondents were asked to complete the questionnaires based on a recently completed project. These respondents are presented in the results section.

For the interviews, snowball and stratified purposeful sampling (covering the six geopolitical zones) were adopted but was drawn from the population of the survey. Eighteen persons were interviewed telephonically for between 41-71 minutes. The respondents of the first few interview sessions suggested people that were invited. The respondents were recruited on the criterion that they must be willing to take part in the study. The respondents were informed of the ethical issues in introductory letters and just before the interviews. This covered, among many, how the data will be used and their right to withdraw from the study. The data collection and analysis were conducted concurrently.

\section{Data Analysis}

For the survey, descriptive (percentages) and inferential statistics (Kruskal-Wallis test and Kendall's tau-b test) using Statistical Package for Social Science (SPSS) were employed in data analysis. Figure 2 expands on Figure 1 and shows the analytical framework for the Kendall's tau-b tests.

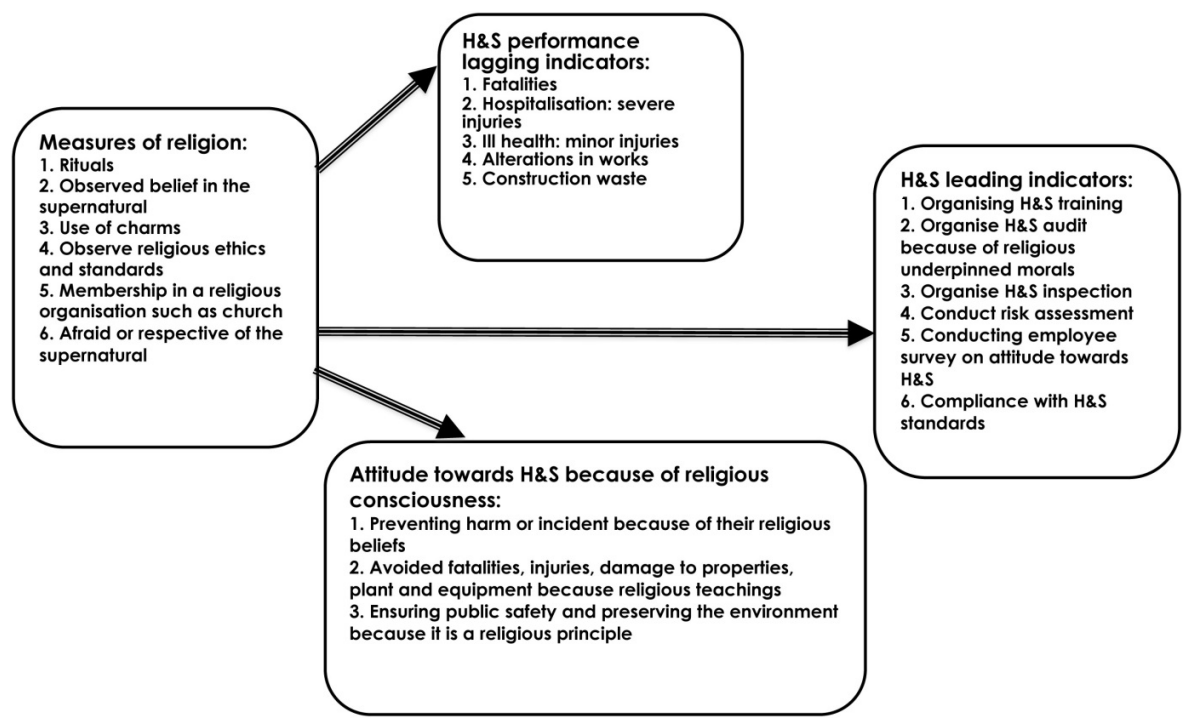

Figure 2. Kendall's Tau-b Test Analysis Framework

For the interviews, using NVivo for Mac, the six-phase thematic analysis by Braun and Clarke (2006) was adopted where the first stage involves reading the transcripts many times so that the analyst, the lead author, would be immersed in the data. This was followed by the second phase, the initial coding of common words. It also involved comparing, asking questions such as "What message is being conveyed here? What is happening here? What is missing here?" This involved lineby-line coding which was both data and theory-driven. The third phase involved arranging the codes into potential themes and subthemes in hierarchical order. 
While the fourth stage involved reviewing the potential subthemes and themes, the fifth stage was re-examining, defining and naming the themes, the last stage was writing up the findings. Importantly, the first five stages were not in a linear form.

In improving the credibility and dependability of the qualitative data, in addition to the aforesaid refinement of the interview protocol, peer debriefing and triangulation were done. The triangulation was of persons and analytical. The analytical triangulation involved constant comparison (within groups and between groups analysis) and computer-aided analysis (Humble, 2009). The groups are those that "Constantly Engaged in H\&S" (CEH\&S) and those that "Do Not Always That Constantly Engaged in H\&S" (non-CEH\&S). Importantly, the interviews also triangulated the survey. The triangulation helped refute, support, illuminate, dissonant and offer full or unique information (Sand and Roer-Strier, 2006).

\section{RESULTS, DISCUSSIONS AND PRACTICAL IMPLICATIONS}

\section{Demographic Profile of Respondents and Details of Projects Reported}

The study established that of the 103 responses to the survey, $35(34 \%)$ were from smallscale contractors (10-29 employees), 49 (47.6\%) from medium-scale contractors (29-199 employees) and 19 (18.4\%) from large-scale contractors (200 and above number of employees). The definition of the categories of contractors is consistent with Kheni (2008). The minimum years of work experience of the respondents are 0-5 years, $19(18.4 \%)$ respondents and the maximum is over 21 years, $25(24.3 \%)$ respondents. Their designations comprised: 18 (17.5\%) architect, 18 (17.5\%) project managers, 17 (16.5\%) safety personnel, 30 (29.1\%) civil engineers and 20 (19.4\%) builders. In terms of the projects reported, 51 (49.5\%) were private buildings, 35 (34\%) commercial buildings, $14(13.6 \%)$ were roads project and three $(2.9 \%)$ were bridges.

For the interviews, of the 18 respondents, four worked for large contractors, seven for medium contracting firms and the rest were engaged by small-scale contractors. There were three architects, five safety personnel, two builders, three quantity surveyors, three project managers and two civil/structural engineers. While their years of experience range from 3.5-20 years and over, two had 3.5 and four years of experience respectively and have worked for consultants for one year. The experiences of the rest cut across various sectors of the industry, for example, building, infrastructure and civil engineering. Some of the respondents from the medium and small firms were owners and managers of the companies but were also construction professionals.

The profile of respondents and the details of projects suggest the reliability of the data. As the respondents are mainly skilled persons, it can be argued that the responses to the questions of the fifth objective may be skewed to the particular group of workers, the professionals or those less exposed to the hazards of the construction activities. The fifth objective is where the input of the operatives could be helpful in improving H\&S through religion. While it can be viewed as the limitation of the study, making room for further studies, there are arguments to support the findings of the study are considered reliable because the respondents of the current study have regular contacts with the operatives hence are likely to understand them. Secondly, the respondents of the present study also have a good understanding of the management structure and hence able to provide 
objective and practical views to the discourse. Thirdly, the professionals are also able to provide both management/skilled and unskilled perspectives - a holistic perspective. Lastly, it is likely that the professionals have started from the lower level of the organisation.

\section{Religiousness in the Projects}

Tables 1 and 2 show strong evidence of religious measures and belief of construction contractors in projects, suggesting the level of confidence the respondents have in religion. Table 1 shows that all but three variables, "The use of charm", "Membership of a religious organisation such as church, mosque" and "Rituals example prayers" have been significantly experienced by the respondents on the reported projects. This is if the midpoint of 2.50 is applied.

However, in terms of the categories of contractors, for the small contractors, all the variables in Table 1 are above the midpoint of 2.5. But for the medium scale contractors, the variables that rank fourth to sixth are below the 2.5 midpoint level. Then for the large contractors, only the religious measures which rank fifth and sixth are below the midpoint of 2.45. Furthermore, the highest-ranking measure of religiousness on projects in Table 1 overall and in terms of the categories of contractors is supported by the findings in Table 2 where there is strong evidence of the belief in the supernatural to do all things.

In the current study, the strong evidence of religious activities in the projects is consistent with the findings of Kheni (2008: 181) who found that "Prayers was often an activity which site workers devoted some time for and often, prayers for work to progress satisfactorily and without any problems can be said". This is expected because Nigerians are highly religious and this is reflective of the society as disclosed elsewhere earlier in this article.

Table 1. Summary of Measure of Religiousness in the Projects

\begin{tabular}{lcccccccc}
\hline $\begin{array}{l}\text { Measure of } \\
\text { Religiousness }\end{array}$ & \multicolumn{2}{c}{ Small Scale } & \multicolumn{2}{c}{ Medium Scale } & \multicolumn{2}{c}{ Large Scale } & \multicolumn{2}{c}{ Overall } \\
\cline { 2 - 8 } & Mean & Rank & Mean & Rank & Mean & Rank & Mean & Rank \\
\hline $\begin{array}{l}\text { Observed belief in } \\
\text { the supernatural }\end{array}$ & 3.94 & 1 & 4.95 & 1 & 4.87 & 1 & 4.60 & 1 \\
$\begin{array}{l}\text { Observed religious } \\
\text { ethics and standards }\end{array}$ & 3.37 & 2 & 2.65 & 3 & 2.75 & 3 & 2.88 & 2 \\
$\begin{array}{l}\text { Afraid or respect for } \\
\text { the supernatural }\end{array}$ & 2.62 & 5 & 2.91 & 2 & 2.89 & 2 & 2.78 & 3 \\
$\begin{array}{l}\text { Use of charms } \\
\begin{array}{l}\text { Membership of a } \\
\text { religious organisation }\end{array}\end{array}$ & 2.65 & 4 & 2.32 & 5 & 2.42 & 5 & 2.45 & 4 \\
$\begin{array}{l}\text { such as a church, } \\
\text { mosque }\end{array}$ & 6 & 2.48 & 4 & 2.71 & 4 & 2.25 & 5 \\
$\begin{array}{l}\text { Rituals: for example, } \\
\text { prayers }\end{array}$ & 3.22 & 3 & 1.79 & 6 & 1.43 & 6 & 2.18 & 6 \\
\hline
\end{tabular}

The Kruskal-Wallis test was conducted to examine whether there is any difference in the responses of the groups, large, medium and small contractors. The 
test shows that of all the factors in Table 1, there are differences in the responses of the respondents on the factor "Rituals: for example, prayer", with a p-value of 0.000 . Hence, the null hypothesis was rejected. To see the exact groups with the differences, a post-hoc test was conducted at a significance level of 0.05 . It shows that there are differences between small and large contractors with a $p$-value of 0.002 and between medium contractors and small contractors with a $p$-value of 0.004. The implication of the results of the Kruskal-Wallis test on the religious measure, "rituals", is that it is unlikely that there is no agreement on the responses of the groups: large, medium and small contractors.

The possible explanation for the differences in the responses of small and large contractors and medium and small contractors in terms of "rituals for example prayers" may be as a result of the differences in the structure of ownership, scope of operation, nature of expertise and difference in corporate culture (cf. Mills and Lin, 2004; Umeokafor, 2016). For example, in small contracting firms, the level of the exhibition of religious beliefs and practices may be more emphasised than in larger contracting organisations. This is because in smaller contractors there is usually a closer tie because of culture within the organisation, the impact of leadership is easily felt (cf. Kheni, 2008; Kheni, Gibb and Dainty, 2010). Hence, if the management joins the rituals, for example, prayer sections, it may encourage other workers to join. This is likely, as the management of small contractors is indigenous, and according to Pew Forum (2010), about $98 \%$ of Nigerians are either Muslims or Christians. This does not mean that in larger contractors that there will be no rituals, but because it is large with a looser tie than the smaller ones and the structure of ownership mixed, Nigerians and foreigners, the religious background may include non-religious people. Hence, management of large contraction organisations may not be as involved in rituals, as it is likely to be in smaller firms.

Also, it can be seen in Table 2 that the respondents claim to have significantly experienced "praying to prevent accidents on construction sites" and "engaging in dangerous activities but praying for safety". While the latter may not be literally as the dangerous activities are going on, Table 2 shows the strong belief in the supernatural to prevent incidents and address implications of incidents. These findings are consistent with Kheni (2008: 183-184) whose findings show that "workers" description of their involvement in accidents or near misses attest to their belief in some supernatural intervention which saved them from death or more severe injury than that which was sustained. This is also consistent with the findings of Umeokafor (2015) elsewhere in this article. Furthermore, the above premise is consistent with the concept of external locus of control. This is where individuals believe that a "higher power such as God or Allah... controls an individual's health outcomes" (Debnam et al., 2012). This contrasts internal locus of control where individuals' belief is that they are responsible for what happened to them (cf. Debnam et al., 2012). Debnam et al. (2012) findings support the association between spiritual health control beliefs and disease prevention and health risk behaviours.

The implications of the above are not only that the H\&S locus of control are external but that the workers or even contractors fail to understand that the locus of control should be balanced. This is where the contractors and workers play their parts in H\&S prior to shifting the locus of control to the supernatural. The question is whether it is possible to balance the locus of control or how to define the balance. Importantly, this is not to dispute the validity of the ability of the supernatural to protect or do all things but to demonstrate that humans have roles to play. 
Furthermore, Table 2 indicates the indirect impact of religion on $\mathrm{H} \& \mathrm{~S}$, as $37.9 \%$ of the respondents have experienced a situation where incompetent persons were employed because of religious relationship. Incompetent workforce results in poor $\mathrm{H} \& \mathrm{~S}$ practices which would then result in poor H\&S performance.

Table 2. Evidence of Religious Underpinned Activities

\begin{tabular}{|c|c|c|c|}
\hline Religious Underpinned Activities & Yes (\%) & No (\%) & Unsure (\%) \\
\hline Prayers to prevent accidents on the construction sites & $74(71.8)$ & $17(16.5)$ & $12(11.7)$ \\
\hline Prayers for the recovery of ill workers in the project & $21(20.4)$ & $59(57.3)$ & $23(22.3)$ \\
\hline $\begin{array}{l}\text { Engaging in dangerous activities but praying for } \\
\text { safety }\end{array}$ & $72(69.9)$ & $19(18.4)$ & $12(11.7)$ \\
\hline $\begin{array}{l}\text { Employing incompetent workers because they are of } \\
\text { the same religious belief or faith with the employer }\end{array}$ & 39 (37.9) & $49(47.6)$ & $15(14.6)$ \\
\hline
\end{tabular}

A few interview respondents from CEH\&S group suggested that in some cases (at least in their projects) observance of ritual is not to transfer the responsibilities of protection to the supernatural. Rather, the points they made centre around praying as a culture, to complement their efforts after they have done all they should do and eliminate human errors. However, many noted that the observance of the rituals was for protection and remedial reasons such as healing of the ill or injured (as shown in Table 2).

\section{How Religion is Practiced to Influence H\&S}

While Table 3 triangulates Tables 1 and 2, it expands on the discourse showing how religion is practiced to influence H\&S. It can be seen in Table 3 that while contractors accommodate the practice of religion and even encourage them, they also shift $\mathrm{H} \& \mathrm{~S}$ responsibilities to the supernatural through rituals, among many, take religious beliefs-driven steps that compromise H\&S. For instance, one respondent from nonCEH\&S narrates:

I was on the (name withheld) project. We were trying to pull down a big tree, at a point the tree fell but the tree destroyed the machine that pulled it down. It... buried the machine inside the ground. This is a man that has been using a bulldozer for a very long time but his tree buried the machine and almost killed the operator. It's just that the operator escaped. This operator is a very old man and knows what he was doing. Even the ... people that were there, directing him, knew the direction they wanted the tree to fall but the tree left that direction instead and fell in such a way as to destroy the machine... I am sure that this was done properly. Before you pull down such trees, you have to make some sacrifices, you have to pay some villagers to make some sacrifices then you can do your work and go.

Probing the above, the respondent stated that the above incident was not investigated because the organisation attributed the near miss to supernatural powers that were not appeased - some sacrifices that were not performed. This is not applicable to all organisations, as a few CEH\&S narrated similar situations where 
there was a thorough incident investigation. Obviously, in the narration above, there are many explanations for the direction the tree fell, but the point here is that these explanations were not considered, as religious-belief driven decisions were taken - not investigating the near miss but sacrificing to the gods.

Another respondent covers the adherence to rituals in unsafe conditions and external locus of control. Indeed, "there was a site we worked on some time ago. When (name withheld) are praying, they face a particular direction (name withheld). We told a man that was praying to give a particular space from the site and change location, he refused. While he was there, it started raining with heavy wind. Everyone left the site for a safe place, but the man continued with his prayers. The wind removed a roofing sheet; it hit the man and he ran away". The respondent goes on to analyse the above concluding that while the worker should pray, he has the responsibility of ensuring his safety and not transferring it to God.

Table 3. How Religion is Practiced to Influence H\&S

\begin{tabular}{|c|c|}
\hline Themes & Evidence \\
\hline $\begin{array}{l}\text { Supporting religious } \\
\text { practices }\end{array}$ & $\begin{array}{l}\text { 1. Large contractors accommodate the practice of religion } \\
\text { more than small firms. } \\
\text { 2. Clients or contractors build places of on-site worship in some } \\
\text { geopolitical zones. } \\
\text { 3. Contractors seek to understand the local religion and beliefs } \\
\text { to ensure successful project. }\end{array}$ \\
\hline $\begin{array}{l}\text { Inevitable observance } \\
\text { of rituals }\end{array}$ & $\begin{array}{l}\text { 1. Observance of rituals - prayers - in unsafe conditions and } \\
\text { trusting the supernatural to protect. } \\
\text { 2. Allocation of prayer times during the work time resulting in } \\
\text { rushing to finish on time. }\end{array}$ \\
\hline $\begin{array}{l}\text { External locus of } \\
\text { control through rituals }\end{array}$ & $\begin{array}{l}\text { 1. Sacrifice for safety of employees before commencement of } \\
\text { work. } \\
\text { 2. Praying for the safety of the employees with little or no steps } \\
\text { to ensure H\&S. } \\
\text { 3. Praying that the supernatural address what may have being } \\
\text { missed out after contractors have done their best. }\end{array}$ \\
\hline $\begin{array}{l}\text { Belief-driven } \\
\text { compromise/ } \\
\text { resistance }\end{array}$ & $\begin{array}{l}\text { 1. Non-investigation of incidents because of certain beliefs. } \\
\text { 2. Change in policy because of religious beliefs, for example, } \\
\text { allowing/using clothing that pose risk while working because } \\
\text { of religious reasons. } \\
\text { 3. Resisting H\&S innovation because of belief. } \\
\text { 4. Large contractors resist pressure to compromise H\&S because } \\
\text { of religious beliefs. }\end{array}$ \\
\hline
\end{tabular}

Impact of Religious Consciousness on H\&S Practices, H\&S Attitude and Performance

\section{Measures of religiousness and lagging indicators}

While Table 1 shows evidence of religious consciousness in construction projects and Table 2 shows the evidence of religious underpinned activities, this section highlights the impact of the aforesaid on H\&S. 
The first was to test if there is an association between measures of religiousness in the projects in Table 1 and Figure 2 and lagging indicators, frequency of fatalities, severe injuries that resulted in hospitalisation, minor injuries, alteration of works due to incidents and construction waste, all in Figure 2. The Kendall's tau-b correlation coefficient test shows that there is a negative correlation between rituals, for example, prayers and alteration of works (tau-b $=-237 ; p=0.004$ ) and rate of construction waste (tau-b $=-288 ; p=0.001$ ). The significance level was set at 0.01 . However, the correlations can be considered as weak.

Possible explanations for the weak correlations between rituals and the rate of construction waste are that while religion "frowns" on waste (Smallwood, 2002), the high level of waste in the Nigerian construction industry reported in Adewuyi, Idoro and Ikpo (2014) may be beyond what only religiousness can underpin or explain (Adewuyi and Odesola, 2015).

At a significance level of 0.05 , the Kendall's tau-b correlation coefficient test shows weak positive correlation between the use of charm, a religious measure and the following lagging indicators: the rate of fatality (tau-b $=0.201 ; p=0.28$ ) and rate of ill health - minor injury (tau-b $=0.185 ; p=0.039$ ). Possible explanations for the weak correlation are that while the belief in charm may result in unsafe practices, it is unable to protect. Further explanation is that there are other factors of ill health and fatality in construction projects.

There was only a weak positive correlation between being afraid or respecting the supernatural, a religious measure and the following lagging indicators: alteration of works and (tau-b $=0.273 ; p=0.001$ ) at a significance level of 0.05 , rate of hospitality (tau-b $=0.260 ; p=0.002$ ) at a significance level of 0.05 and the rate of ill health - minor injury (tau-b $=0.182 ; 0.029$ ) at a significance level of 0.01 .

The high level of religious consciousness as evidenced in Tables 1 and 2 is supported by the results of the Kendall's tau-b test. The implication of the results of the Kendall's tau-b test is that where there is negative correlation, one variable increases as the other decreases and vice versa. On the other hand, those with a positive correlation, imply that when religious measures increase, the lagging indicators also increase. By implication, it is highly unlikely that religiousness would not significantly impact H\&S performance of the contractors in terms of lagging indicators.

\section{Measures of religiousness and leading indicators}

Furthermore, there was another Kendall's tau-b test between measures of religiousness in the projects in Table 1 and leading indicators: frequency of organising $\mathrm{H} \& \mathrm{~S}$ training, audit organising H\&S because of religious underpinned morals, inspections, conducting risk assessment, conducting employee survey on attitude towards H\&S and compliance with H\&S standards. At a significance level of 0.01 , the test showed weak negative correlation between religious measure, membership of a religious organisation and the following leading $\mathrm{H} \& \mathrm{~S}$ indicators: organising H\&S training (tau-b $=-209 ; p=0.12$ ), carrying out H\&S audit (tau-b = $-169 ; p=0.047$ ) and conducting H\&S inspection (tau-b $=-172 ; p=0.039$ ). Then, $a t$ a higher significance level, 0.05, there was a weak negative correlation between compliance with H\&S standard, a leading $\mathrm{H} \& \mathrm{~S}$ indicator and a religious measure, observing religious ethics and standards (tau-b $=-230 ; p=0.005$ ).

The high level of religious consciousness in Tables 1 and 2 triangulates the results of Kendall's tau-b test in the preceding paragraphs. The implications or 
meanings of negative and positive correlation in the last paragraph of the "Measures of religiousness and lagging indicators" section are replicated here but in terms of leading indicators. In other words, in terms of the leading indicators, the significant impact of religiousness on H\&S performance is highly likely.

The leading H\&S indicators are meant to ensure the H\&S of workers and other people that may be affected by construction activities. Consequently, it is logical to conclude that the findings of the present study is consistent with the findings of Debnam et al. (2012) elsewhere in this article which support the association between spiritual health control beliefs and disease prevention and health risk behaviours. It is also in agreement with the previous study by Allegranzi et al. (2009) which found a link between controlling infections, contamination with substances hazardous to health and religion.

An explanation to the strong presence of religiousness in Tables 1 and 2 but with weak correlation with $\mathrm{H} \& \mathrm{~S}$ practices variables and H\&S performance variables may be that religion is now more like a culture without people reflecting on its principles that foster H\&S as demonstrated by Eckhardt (2001). Morals will mean different things to different people (Smallwood, 2002). Also, the principles of religion in the literature review may be relative to people.

\section{Measures of religion and attitudes towards H\&S due to religious consciousness}

While the above two experiments addressed objective two, the measures of religiousness in the projects and religious underpinned activities are addressed in objective one. In addressing objective three, another Kendall's tau-b test was conducted between measures of religiousness (as shown in Table 1) and H\&S attitude due to religiousness. The attitudes are the frequency of management doing the following because of religious beliefs or principles thus: preventing harm or incidents in the project, avoiding fatalities, injuries, damage to properties, plant and equipment, ensuring public safety and preserving the environment.

The result shows a positive correlation between observed belief in the supernatural and the following variables: employers avoiding fatalities, injuries, damage to properties, plant and equipment (tau-b $=0.168 ; p=0.43$ ) at $a$ significance level of 0.05 , preventing harm or incidents in the project (tau-b $=0.256$; $p=0.002$ ) at a significance level of 0.01 and ensuring public safety and preserving the environment because both are underpinned by the principles of religion (tau-b $=0.248 ; p=0.003$ ) at a significance level of 0.01 .

Furthermore, the Kendall's tau-b correlation coefficient test shows a positive correlation between observed religious ethics and standards, and employer preventing harm or incidents in the project (tau-b $=0.166 ; p=0.43$ ), ensuring public safety and preserving the environment (tau-b $=0.166 ; p=0.045$ ) all at significance level of 0.05 and employers avoiding fatalities, injuries, damage to properties, plant and equipment (tau-b $=0.223 ; p=0.007$ ) at a significance level of 0.01 .

According to the Kendall's tau-b test, there was a positive correlation between the fear or respect of the supernatural, a measure of religion and employer preventing harm or incidents in the project (tau-b $=0.221 ; p=0.007$ ) at a significance level of 0.01 and avoid fatalities, injuries, damage to properties, plant and equipment (tau-b $=0.296 ; p=0.000$ ) at a significant level of 0.05.

The implications of the results of the Kendall's tau-b test in the preceding paragraphs, religious measures and attitudes towards H\&S because of religious consciousness, is the same as noted in the preceding subsection. This is where if 
there is a negative correlation it means that one variable increases as the other decreases and vice versa. Conversely, those with a positive correlation mean that when religious measures increase, the attitudes towards $\mathrm{H} \& \mathrm{~S}$ because of religious consciousness also increase. In other words, it is highly unlikely that religiousness would not significantly impact on contractors attitudes towards H\&S.

\section{Ways of Improving H\&S through Religion}

Fifty-three respondents (51.5\%) agreed that religion can improve H\&S, but 20 (19.4\%) disagree and $30(29.1 \%)$ were unsure. The interviews triangulate these findings in terms of convergence, completeness and unique information. In particular, some respondents noted that religion cannot be a medium for improving H\&S. Their responses are not limited to "H\&S and religion are parallel", "Religion is about faith while H\&S is science" and "Not sure there can be a meeting point for both". However, probing their responses, a few suggested or changed their position because of the moral teachings or principles of religion, which is consistent with the principles of $\mathrm{H} \& S$. Some respondents agreed that religion could be a medium for improving H\&S.

Meanwhile, the above including the statistics in the above paragraph were probed and the qualitative data in Table 4 and the statistical results presented in Table 5. Table 4 shows the emerging themes and evidence from the interviews on the views of respondents on how to improve H\&S through religion. It shows the roles of academics, policymakers and religious leaders who are viewed as having religious underpinned responsibilities. The data shows that while the respondents emphasised that religious leaders should include H\&S in their teachings, there is evidence that it is already being practised in places of worship. According to one of the respondents:

The iman and pastor use their teaching to educate people on H\&S when they are preaching in the mosques or churches. For example, I went to a church and after the services, the church played a little (VIDEO) tape for the members on the safe crossing of the road. They showed members wrongfully crossing of the express road (motorway) instead of using the pedestrian crossing. This is what the members do to cross and the risk is very high. They ... told them that crossing the road like that is bad and that they are disobeying the laws of the land. This is where the laws stated that crossing an express road must be via a pedestrian crossing when available. If pastors and imans, etc. will use such for H\&S, people may hear them—they have the spiritual voice.

While the above narrative provides evidence that using religious leaders as a medium for improving safety is already happening, it provides an assurance on the workability of the premise. It also highlights the spiritual position of spiritual leaders (who can significantly influence subjects) which can be exploited to the advantage of H\&S. While it could be asked "How do we get spiritual leaders involved?", Table 4 shows that they have spiritual underpinned responsibilities which can be arguments used in persuading them to take part in improving H\&S performance. 
Table 4. Results of Interviews on the Ways of Improving H\&S Performance through Religion

\begin{tabular}{ll}
\hline Themes & Evidence \\
\hline Suggested stakeholders & $\begin{array}{l}\text { 1. Religious leaders cover H\&S in their teachings in religious } \\
\text { places of worship making moral arguments and } \\
\text { responsibilities. }\end{array}$ \\
& $\begin{array}{l}\text { 2. Academics and policymakers can be a medium for } \\
\text { improving H\&S. }\end{array}$ \\
Content of H\&S teachings & $\begin{array}{l}\text { 1. Moral underpinned H\&S teachings. } \\
\text { 2. Use scriptures that support H\&S to make strong arguments } \\
\text { - religious leaders. }\end{array}$ \\
& $\begin{array}{l}\text { 3. Considering the types of religion in H\&S policies and } \\
\text { equipment. }\end{array}$ \\
Convincing religious & $\begin{array}{l}\text { 1. Exploit spiritual position and influence of spiritual leaders. } \\
\text { leaders }\end{array}$ \\
Reporting & $\begin{array}{l}\text { Report management of firms with poor H\&S performance } \\
\text { to traditional/religious leaders. }\end{array}$ \\
\hline
\end{tabular}

Table 5 shows that many of the respondents are positive that religion can contribute to improving H\&S. This opinion is emphasised by the fact that overall and across all the categories of contractors, large, medium and small, all the factors are ranked above the midpoint of 2.5 (as shown in Table 5). Also, the literature review section reveals or demonstrates how religion improves $\mathrm{H} \& \mathrm{~S}$. This includes the religious underpinning for a safe workplace (Eckhardt, 2001), the teachings of religion (Kheni, 2008; Smallwood, 2002), the basis of the elements of religion such as morals, punishment for sins of which negligence of the H\&S of people can be considered as one. According to Pukenis (2014), involving religious leaders can be a way of tackling problems in the society.

The high number of positive views in Table 5 on the ways of improving H\&S through religion offers optimism. That the impact of religion is yet to be felt on the daily activities of religious conscious people does not however support positive views. For instance, Nigeria ranked 136 out of 176 countries in terms of corruption in the Transparency International's Perception Corruption Index of 2014 (Transparency International, 2014). Umeokafor (2015) even posits that corruption has been redefined in Nigeria, making corrupt practices to be socially acceptable. However, this point does not negate using religion as a medium for improving H\&S.

Furthermore, "Reporting members of the management of organisations with poor H\&S records to their religious organisations" in Table 5 seems like a good idea, more like damaging the images of the organisation, a negative reputation management approach. But the extent that this approach can positively influence the management of organisations has been questioned by authors such as Diugwu (2008). Diugwu would rather see promoting the image of organisations with good H\&S records and positive reputation management approach (Diugwu, 2008). Business decisions are determined by many factors hence, the management of the organisations may lack the ability to engage in H\&S even if they want to (Umeokafor, 2016).

Another point to consider in terms of Table 5 is that religion is sensitive hence there is a risk of crossing that sensitive line in terms of the factor, "Encouraging teachers of religion to outline/highlight H\&S issues in their religious teachings". 
Nonetheless, considering the support for the premise in this section and the literature review section, it is worth a try.

Table 5. Descriptive Statistics Output of the Ways for Improving H\&S Performance

\begin{tabular}{|c|c|c|c|c|c|c|c|c|}
\hline \multirow{2}{*}{$\begin{array}{l}\text { Suggested Ways } \\
\text { for Improving H\&S }\end{array}$} & \multicolumn{2}{|c|}{ Small Scale } & \multicolumn{2}{|c|}{ Medium Scale } & \multicolumn{2}{|c|}{ Large Scale } & \multicolumn{2}{|c|}{ Overall Rank } \\
\hline & Mean & Rank & Mean & Rank & Mean & Rank & Mean & Rank \\
\hline $\begin{array}{l}\text { Reporting } \\
\text { members of the } \\
\text { management of } \\
\text { organisations with } \\
\text { poor H\&S records } \\
\text { to their religious } \\
\text { organisations }\end{array}$ & 2.51 & 5 & 4.40 & 1 & 2.63 & 3 & 3.43 & 1 \\
\hline $\begin{array}{l}\text { Encouraging } \\
\text { teachers of } \\
\text { religions to } \\
\text { outline/highlight } \\
\text { H\&S issues in their } \\
\text { religious teachings }\end{array}$ & 3.08 & 2 & 3.59 & 2 & 3.31 & 2 & 3.36 & 2 \\
\hline $\begin{array}{l}\text { Embedding } \\
\text { religions traditions } \\
\text { in H\&S teachings }\end{array}$ & 3.22 & 1 & 3.36 & 3 & 3.31 & 2 & 3.31 & 3 \\
\hline $\begin{array}{l}\text { Incorporating } \\
\text { religious } \\
\text { underpinned } \\
\text { moral teachings in } \\
\text { toolbox talks }\end{array}$ & 3.05 & 3 & 3.22 & 5 & 3.31 & 2 & 3.18 & 4 \\
\hline $\begin{array}{l}\text { Religiously } \\
\text { underpinning } \\
\text { H\&S sensitisation } \\
\text { programs }\end{array}$ & 2.80 & 4 & 3.28 & 4 & 3.42 & 1 & 3.14 & 5 \\
\hline
\end{tabular}

To further interrogate the data in Table 5, the Kruskal-Wallis test was conducted to examine whether there is any difference in the responses of the groups, large, medium and small contractors. The test shows that of all the factors in Table 5, there are differences in the responses of the groups on the factor "Reporting members of the management of organisations with poor H\&S records to their religious organisations", with a p-value of 0.004 . Hence, the null hypothesis was rejected. To see the exact groups with the differences, a post-hoc test was conducted at a significance level of 0.05 . It showed a difference between small and medium contractors with a p-value of 0.006 . The implications of the Kruskal-Wallis test is that it is unlikely that there is no agreement on the responses of the groups, medium and small contractors on the factor "Reporting members of the management of organisations with poor H\&S records to their religious organisations" hence not by chance.

Possible explanations for the difference in the views of small and mediumscale contractors are not limited to the following. Firstly, the implications of "Reporting members of the management of organisations with poor H\&S records to their religious organisations" may be different for both types of contractors. The 
reaction of the two types of contractors and their resilience level to the implications of reporting them to a religious organisation is likely to be different. Secondly, the smaller contractors who may have a closer tie with its employees may be able to stop or dictate the likelihood of reporting than the medium scale contractors where the tie between employers and workers may be weaker. To one of the types of contractors, reporting them may be more effective or less effective. Thirdly, considering the difference in the two types of contractors, for example ability to secure loans (Windapo and Jegede, 2013), ability to engage in H\&S (Kheni, Dainty and Gibb, 2007), scope of operation, annual turnover, size of employees: it may be naive to assume that the same strategy may work for both. The fourth point may be the difference in the motives or drivers to H\&S among, large, medium and small contractors. Drawing on authors such as Wright (1998), Kheni, Dainty and Gibb (2007) and Vickers et al. (2005), Umeokafor (2016) shows that while SMEs would engage in $\mathrm{H} \& \mathrm{~S}$ because of family values, large contractors would engage in $\mathrm{H} \& \mathrm{~S}$ because of social and business reputation.

\section{Practical Implications of the Research}

The research implications include factoring in religious arguments for improving $\mathrm{H} \& \mathrm{~S}$ in the development of education curricula, a point for academics and policymakers. Based on the potential of religion to improve H\&S in the literature review which is supported by empirical evidence, it is logical to consider the foregoing point. Also, the presence of religion and that it underpins some activities of the contractors also make a case for the foregoing premise. Academics, policymakers and contractors are now aware of the implications or potential of the religious consciousness of Nigerians on H\&S. The role of the possible contribution of religious leaders in improving $\mathrm{H} \& \mathrm{~S}$ is emphasised in the study. In improving $\mathrm{H} \& \mathrm{~S}$ in developing countries, studies such as Kheni (2008), Umeokafor and Windapo (2016) argue or demonstrate the imperativeness of understanding the contexts of countries for without which H\&S improvement measures may not be effective. The findings of the current study advance the understanding of the religious context of Nigeria with implications for improving H\&S not only construction H\&S. Policymakers and academics could find this beneficial. The study also provides a novel alternative or consideration in the efforts towards improving H\&S in Nigeria.

While the evidence in the current study is from Nigeria, based on the arguments of authors such as Kheni, Gibb and Dainty (2010), other countries, especially developing countries, are highly likely to benefit from the study. Drawing on Hillebrandt (1999), Ofori (1999), Thomas (2002) and Kheni, Gibb and Dainty (2010) argue that developing countries share the same features in terms of the methods of construction, regulatory system, technology and cultural environment. The study can also serve as a framework for exploring the discourse in country specific perspectives, bedrock for further studies.

\section{CONCLUSION AND RECOMMENDATIONS}

The study reported in this article aimed at assessing the impact of religious consciousness on construction H\&S practices, H\&S attitudes and performance and explained how religion is practiced to influence H\&S. It also identified, assessed and explained possible ways of utilising religion as an H\&S improvement tool. Using 
mixed methods research approach that employs both questionnaires and interview protocol in data collection, the study shows a strong presence of the elements of religion such as observed belief in the supernatural, observed religious ethics and standards in construction contractors. While the religious underpinned activities such as praying to prevent accidents on construction activities, support this, they show the belief of the workers and contractors in the supernatural to protect. However, rituals and belief were established as being viewed differently by small and large contractors and between medium and small contractors. The study goes on to show the weak correlation between the elements of religion, for example, the observed belief in the supernatural, on the leading and lagging indicators of $\mathrm{H} \& S$. These include carrying out H\&S audit, organising H\&S training and conducting $\mathrm{H} \& \mathrm{~S}$ inspections - leading H\&S indicators. The lagging indicators are not limited to alteration of works, the rate of fatality and rate of construction waste. The impact of religiousness was also shown on the attitudes of the contractors towards H\&S. This is where there was a weak correlation between the elements of religion, such as observed belief in the supernatural and the attitudes, prevent harm or incidents on the project. Overall, three different religious measures correlate with nine lagging indicators of which some such as ill health was found to correlate with more than one religious measure. Also, one religious measure, membership in a religious organisation, correlated with three leading indicators.

However, the high number of responses that religion can be instrumental to improving H\&S offers optimism, especially as Nigeria is a highly religious nation. However, this can only be achieved if the moral stance of all is the same, but this is impossible. Although this study is reported from a developing country perspective, developed countries can also benefit from the contribution to knowledge in that it highlights areas in H\&S practices that can be improved through religion and the influence of religion on $\mathrm{H} \& \mathrm{~S}$.

Drawing on the literature review, the results and discussions, the following are recommended. First, as literature review shows the potential of religion to improve $\mathrm{H} \& \mathrm{~S}$ and this is supported by empirical evidence, policymakers, academics and religious leaders now have moral obligations to support or consider factoring in religion in the activities that are geared towards improving H\&S. Second, the literature review demonstrates the support of religion for $\mathrm{H} \& \mathrm{~S}$ and the aspects of religion which support it. For example, morality and the research findings support the role that religion plays in improving H\&S performance. Thus, it is recommended that the recommendations of the respondents outlined in Table 5 are considered by policymakers, academics and religious leaders.

Among the limitations of this study is that the religions of the sample population are mostly Christianity and Islam. This may, therefore, mean that only the perceptions of the two major religions in Nigeria have been presented. Nonetheless, the insight that this study offers is revealing. Another limitation is the lack of records, which may have affected the objectivity of the data, but the non-parametric tests have reduced the effect of this limitation on this study. Further studies may seek to understand the impact of religion from an interpretivist perspective. 


\section{REFERENCES}

Adewuyi, T.O. and Odesola, I.A. (2015). Factors affecting material waste on construction sites in Nigeria. Journal of Engineering and Technology, 6(1): 82-99.

Adewuyi, T.O., Idoro, G.I. and Ikpo, I.J. (2014). Empirical evaluation of construction material waste generated on sites in Nigeria. Civil Engineering Dimension, 16(2): 96-103. https://doi.org/10.9744/ced.16.2.96-103.

Allegranzi, B., Memish, Z. A., Donaldson, L. and Pittet, D. (2009). Religion and culture: Potential undercurrents influencing hand hygiene promotion in health care. Association for Professionals in Infections Control and Epidemiology, 37(1): 28-34. https://doi.org/10.1016/j.ajic.2008.01.014.

Allen, S. (2012). Sociology of religion. Available at: http://www.slideshare.net/ sethallen26/sociology-of-religion [Accessed on 12 September 2015].

American Bureau of Shipping (ABS) (2012). Guidance Note on Safety Culture and Leading Indicators of Safety. Texas: ABS. Available at: https://www.eagle.org/ eagleExternalPortalWEB/ShowProperty/BEA\%20Repository/Rules\&Guides/ Current/188_Safety/Guide [Accessed on 28 October 2015].

Braun, V. and Clarke, V. (2006). Using thematic analysis in psychology. Qualitative Research in Psychology, 3(2): 77-101.

Castillo-Montoya, M. (2016). Preparing for interview research: The interview protocol refinement framework. The Qualitative Report, 21 (5): 811-831.

Dabup, N.L. (2012). Health, safety and environmental implications in Nigeria's oil and gas industry. PhD diss. Nelson Mandela Metropolitan University.

Debnam, K.J., Holt, C.L., Clark, E.M., Roth, D.L., Foushee, H.R., Crowther, M., Fouad, M. and Southward, P.L. (2012). Spiritual health locus of control and health behaviors in African Americans. American Journal of Health Behavior, 36(3): 360-372. https://doi.org/10.5993/ajhb.36.3.7.

Diugwu, I.A. (2008). A framework to evaluate critically health and safety strategies in supply chains in the UK. PhD diss. Coventry University.

Eckhardt, R.F. (2001). The moral duty to provide workplace safety. Professional Safety, 4(8): 36-38.

Government of Federal Republic of Nigeria (1999). Constitution of the Federal Republic of Nigeria. Available at: http://www.wipo.int/edocs/lexdocs/laws/ en/ng/ng014en.pdf [Accessed on 23 July 2017].

Health and Safety Executive (HSE). (2017). Fatal Injuries Arising from Accidents at Work in Great Britain 2017. Merseyside, England: HSE. Available at: http:// www.hse.gov.uk/statistics/pdf/fatalinjuries.pdf [Accessed on 23 July 2017]. . (2015). Health and Safety in Construction Sector in Great Britain, 2014/15. Merseyside, England: HSE. Available at: http://www.hse.gov.uk/statistics/ industry/construction/construction.pdf [Accessed on 28 October 2015]. . (2014). Health and Safety in Construction in Great Britain. Merseyside, England: HSE. Available at: http://www.hse.gov.uk/Statistics/industry/ construction/construction.pdf [Accessed on 8 October 2015].

Hillebrandt, P. (1999). Choice of technologies and inputs for construction in developing countries. In Construction Industry Development in the New Millennium, Proceedings of the Second International Conference on Construction Industry Development. Singapore: University of Singapore.

Hughes, P. and Ferrett, E. (2011). Introduction to Health and Safety at Work. 5th Ed. London: Elsevier. 
Humble, A.M. (2009). Technique triangulation for validation in directed content analysis. International Journal of Qualitative Methods, 8(3): 34-51. https://doi. org/10.1177/160940690900800305.

Idoro, G.I. (2012). Influence of the monitoring and control strategies of indigenous and expatriate Nigerian contractors on project outcome. Journal of Construction in Developing Countries, 17(1): 49-67.

- Comparing occupational health and safety (OHS) management efforts and performance of Nigerian Construction Contractors. Journal of Construction in Developing Countries, 16(2): 151-173.

Kheni, N.A. (2008). Impact of health and safety management on safety performance of small and medium-sized construction business in Ghana. PhD diss. Loughborough University.

Kheni, N.A., Dainty, A.R.J. and Gibb, A.G.F. (2007). Influence of political and sociocultural environments on health and safety management within SMEs: A Ghana case study. In D. Boyd (ed.), Proceedings of the 23rd Annual Association of Researchers in Construction Management (ARCOM) Conference. Belfast: ARCOM, 159-168.

Kheni, N.A., Gibb, A.G.F. and Dainty, A.R.J. (2010). The health and safety management within small and medium-sized enterprise (SMEs) in developing countries: Study of contextual influence. Journal of Construction Engineering and Management, 136(10): 1104-1115. https://doi.org/10.1061/(asce) co.1943-7862.0000218.

Marosszeky, M., Karim, K., Davis, S. and Naik, N. (2004). Lessons learnt in development effective performance measures for construction safety management. In S. Bertelsen and C.T. Formoso (eds.), Proceedings of the 12th Annual Conference of the International Group for Lean Construction (IGLC). Helsingør, Denmark: IGLC.

Mills, A. and Lin, J. (2004). Effect of company size on occupational health and safety. The International Journal of Construction Management, 4(1): 29-39.

Mookerjee, R. and Beron, K. (2005). Gender, religion and happiness. The Journal of Socio-Economics, 34(5): 674-685. https://doi.org/10.1016/j.socec.2005.07.012.

New International Version of the Bible (2011). Deuteronomy 22:8. Available at: https://www.biblegateway.com/passage/? search=Deuteronomy+22:8 [Accessed on 11 October 2015].

Pew Forum (2010). Appendix B: Religious Demography of Sub-Saharan Africa. Washington DC: Pew Research Center. Available at: http://www.pewforum. org/files/2010/04/sub-saharan-africa-appendix-b.pdf [Accessed on 23 July 2017].

Pukenis, R. (2014). Christian religion in the globalised world of the 21 st century. European Scientific Journal, 10(17): 37-19.

Ruby, R. and Shah, T.S. (2007). Nigeria's Presidential Election: The Christian-Muslim Divide, 21 March. Washington DC: Pew Research Center. Available at: http:// www.pewforum.org/2007/03/21/nigerias-presidential-election-the-christianmuslim-divide/ [Accessed on 23 July 2017].

Sands, R.G. and Roer-Strier, D. (2006). Using data triangulation of mother and daughter interviews to enhance research about families. Qualitative Social Work, 5(2): 237-260. https://doi.org/10.1177/1473325006064260. 
Sgourou, E., Katsakiori, P., Goutsos, S. and Manatakis, E. (2010). Assessment of selected safety performance evaluation methods in regards to their conceptual, methodological and practical characteristics. Safety Science, 48(8): 1019-1025. https://doi.org/10.1016/j.ssci.2009.11.001.

Shariff, A.F. and Rhemtulla, M. (2012). Divergent effects of beliefs in heaven and hell on national crime rates. PLos One, 7(6): 1-5. https://doi.org/10.1371/journal. pone.0039048.

Shaw, A. (1994). OHS performance indicators for benchmarking report on the literature review conducted as stage 1 of the Worksafe Australia project to develop a benchmarking methodology for occupational health and safety. In Positive Performance Indicators for OHS: Beyond Lost Time Injuries; Part 1-Issues. Canberra: Worksafe Australia. Available at: http://www. safeworkaustralia.gov.au/sites/swa/about/publications/Documents/99/ PositivePerformancelndicators_OHS_BeyondLostTimelnjuriesPart\%20 1-Issues_1994_ArchivePDF.pdf [Accessed on 28 October 2015].

Smallwood, J. (2002). Health and safety (H\&S) and religion: Is there a link? In S. Rowlinson (ed.), Proceedings of the Triennial Conference International Council for Research and Innovation in Building and Construction (CIB) W099 Implementation of Safety and Health on Construction Site. Delft, The Netherlands: CIB.

Transparency International (2014). Transparency International Corruption Perceptions Index 2014. Berlin: Transparency International. Available at: http://www.ey.com/Publication/vwLUAssets/EY-transparency-internationalcorruption-perceptions-index-2014/\$FILE/EY-transparency-internationalcorruption-perceptions-index-2014.pdf [Accessed on 12 October 2015].

Umeokafor, N.I. (2017). An appraisal of the barriers to client involvement in health and safety in Nigeria's construction industry. Journal of Engineering, Design and Technology, 15(4): 471-487. https://doi.org/10.1108/jedt-06-2016-0034.

- (2016). Approaches, drivers and motivators to health and safety selfregulation in the Nigerian construction industry: A scoping study. Architectural Engineering and Design, 12(6): 460-475. https://doi.org/10.1080/17452007.20 16.1195332.

- (2015). An assessment of the influence of contextual environment on health and safety practices in the Nigerian construction industry. In M. Behm and C. McAleenan (eds.), Proceedings CIB W099 International Health and Safety Conference: Benefitting Workers and Society through Inherently Safe(r) Construction. Belfast: EEl Publishing, 397-406.

Umeokafor, N.I. and Windapo, A.O. (2016). A framework for managing contextual influence on health and safety on construction projects. In A.O. Windapo, S.J. Odediran and A. Adediran (eds.), Proceedings: 9th Construction Industry Development Board (CIDB) Postgraduate Conference. Cape Town: University of Cape Town, 285-294.

United Sates Embassy in Nigeria (2012). Nigeria Fact Sheet. Abuja, Nigeria: United Sates Embassy in Nigeria. Available at: http://photos.state.gov/libraries/ nigeria/487468/pdfs/Nigeria\%20overview\%20Fact\%20Sheet.pdf [Accessed on 23 July 2017].

Vickers, I., James, P., Smallbone, D. and Baldock, R. (2005). Understanding small firms responses to regulation: The case of workplace health and safety. Policy Studies, 26(2): 149-169. https://doi.org/10.1080/01442870500127626. 
Waziri, B.S., Hamma-Adama, M. and Kadai, B. (2015). Exploring health and safety practices on some Nigeria construction site. In S. Laryea and R. Leiringer (eds.), Procs 6th West Africa Built Environment Research (WABER) Conference. Johannesburg: WABER Conference, 491-502.

Windapo, A.O. and Jegede, O.P. (2013). A study of health, safety and environment (HSE) practices of Nigerian construction companies. The Professional Builder, 4(1): 92-103.

Wright, M.S. (1998). Factor Motivating Health and Safety Management: Health and Safety Executive (HSE) Contract Research Report 179/1998. Norwich, England: HSE Books.

Yamane, T. (1967). Statistics: An Introductory Analysis. 2nd Ed. New York: Harper and Row. 